\title{
MicroRNA-93 inhibits chondrocyte apoptosis and inflammation in osteoarthritis by targeting the TLR4/NF-кB signaling pathway
}

\author{
YANJIE DING, LAIFANG WANG, QING ZHAO, ZHENZHEN WU and LINGLI KONG
}

Department of Rheumatology and Immunology, Huaihe Hospital of Henan University, Kaifeng, Henan 475000, P.R. China

Received June 23, 2018; Accepted December 7, 2018

DOI: $10.3892 /$ ijmm.2018.4033

\begin{abstract}
Osteoarthritis (OA) is a serious disease of the articular cartilage, and inflammation has been implicated in its pathogenesis. Previously, microRNAs (miRNAs) have been proposed as novel regulators of inflammation, however, the functional role of microRNAs in regulating inflammation in OA remains to be fully elucidated. The aim of the present study was to investigate the roles of miRNAs in OA inflammation and the underlying molecular mechanism. Firstly, the miRNA expression patterns were analyzed in the articular cartilage tissues from experimental OA mice using an miRNA microarray. miRNA (miR)-93 was identified with particular interest due to its reported effects on apoptosis and inflammation suppression. Subsequently, the expression of miR-93 was further validated in the articular cartilage tissues of $\mathrm{OA}$ mice and lipopolysaccharide (LPS)-stimulated primary chondrocytes. Using this LPS-induced chondrocyte injury model, the overexpression of miR-93 enhanced cell viability, improved cell apoptosis and attenuated the inflammatory response, as reflected by reductions in pro-inflammatory cytokines, including tumor necrosis factor (TNF)- $\alpha$, interleukin (IL)- $1 \beta$ and IL-6. In addition, Toll-like receptor 4 (TLR4), an important regulator of the nuclear factor- $\kappa \mathrm{B}(\mathrm{NF}-\kappa \mathrm{B})$ signaling pathway, was identified as a direct target of miR-93 in chondrocytes. Furthermore, the restoration of TLR4 markedly abrogated the inhibitory effects of miR-93 on the chondrocyte apoptosis and inflammation induced by LPS. In addition, the overexpression of miR-93 by agomir-miR-93 significantly inhibited the levels of pro-inflammatory cytokines and cell apoptosis, whereas antagomir-93 exacerbated apoptosis and inflammation in vivo. Taken together, the results of the study suggested that miR-93 may be a promising therapeutic target for the treatment of human OA.
\end{abstract}

Correspondence to: Dr Qing Zhao, Department of Rheumatology and Immunology, Huaihe Hospital of Henan University, 115 Ximen Street, Kaifeng, Henan 475000, P.R. China

E-mail: qinzhaoqz@163.com

Key words: osteoarthritis, apoptosis, inflammation, microRNA-93, TLR4/NF- $\mathrm{B}$ signaling pathway

\section{Introduction}

Osteoarthritis (OA) is a type of degenerative joint disease, which is primarily characterized by the progressive destruction of articular cartilage and joint inflammation, leading to physical disability and decreased quality of life (1). This disease affects $\sim 80 \%$ of the population aged $\geq 60$ years and accounts for high annual hospitalizations in the developed world (2). Chondrocytes, the only cells in articular cartilage, are critical in the pathological progression of OA via apoptosis and cytokine production $(3,4)$. Therefore, the alleviation of chondrocyte apoptosis and inflammation can be an effective therapeutic intervention in patients of OA.

MicroRNAs (miRNAs) are small ( 22 nucleotides) non-coding RNA molecules, which typically inhibit the translation and target the degradation of mRNAs through partial complementarity $(5,6)$. A large body of evidence indicates that miRNAs are frequently dysregulated in human inflammatory diseases, including OA, and that these miRNAs are important in cartilage degradation $(7,8)$. Specifically, a list of miRNAs differentially expressed in plasma in primary OA has been identified in inflammatory disorders (9). For example, miRNA (miR)-9 was found to be downregulated in the cartilage tissues of OA rats and the upregulation of miR-9 inhibited the expression level of matrix metalloproteinase-13 (MMP-13), decreased its suppressive effects on collagen type II $\alpha 1$ (Col2A1), and contributed to antagonizing OA (10). Another study showed that the upregulation of miR-218-5p protected OA mice from cartilage degradation by inhibiting the phosphoinositide 3-kinase/Akt/mammalian target of rapamycin signaling pathway (11). miR-210 negatively regulates the lipopolysaccharide (LPS)-induced production of pro-inflammatory cytokines by targeting nuclear factor- $\mathrm{\kappa} B$ (NF-kB) in murine macrophages (12). However, limited studies have focused on the role of miRNAs in the inflammatory pathogenesis of OA.

In the present study, an miRNA microarray was performed to investigate miRNA expression profiles in an OA mice model. Subsequently, the regulatory mechanisms of miR-93 on inflammatory response and apoptosis were examined in an LPS-induced chondrocyte injury model. Subsequently, the improvement of the inflammatory response and apoptosis induced by miR-93 in OA mice was verified. Finally, it was found that miR-93 targeted TLR4 and inhibited activation of the NF- $\mathrm{KB}$ pathway in vitro and in vivo. These findings provide 
information for the future direction of treatments for patients with OA.

\section{Materials and methods}

Animals. A total of 36 male (n=6/group), eight-week-old C57BL/6 mice weighing 20-25 g (Joint Ventures Sipper BK Experimental Animal Company, Shanghai, China) were kept under standard animal room conditions (temperature, $23 \pm 1^{\circ} \mathrm{C}$; humidity, $55 \pm 5 \%$ ) in a 12 -h light/dark cycle and fed a standard laboratory diet and water ad libitum. The animal use and experimental protocols were approved by the Animal Care Committee of the Huaihe Hospital of Henan University (Kaifeng, China) in accordance with the institutional guidelines.

In vivo experiment. The miR-93 agomir and agomir-negative control (agomir-NC) were obtained from GenePharma. The mice were randomly divided into four groups, a sham group, an OA group, an OA + agomir-miR-93 group and an OA + agomir-NC group. In the OA group (n=6/group), the mice were subjected to MMT. Mice subjected to sham surgery were used in the sham group. In the OA + agomir-miR-93 group ( $n=6 /$ group), the mice were treated with agomir-miR-93 $(5 \mathrm{nmol})$ via intra-articular injection administered through a medial parapatellar approach at 1 week post-surgery (13). The mice were subjected to MMT and treated with agomir-NC as the negative control. After 2 weeks, all mice were sacrificed following induction of deep anesthesia, and the articular cartilages of the medial tibial plateau and the synovial fluid were collected for further experiments.

Isolation of primary mouse articular chondrocytes and treatment. The primary chondrocytes were harvested from articular cartilage as previously described (7). Briefly, the articular cartilage were cut finely into $1-3 \mathrm{~mm}^{3}$ slices with a scalpel blade, digested with $0.25 \%$ trypsin including $0.01 \%$ EDTA for $30 \mathrm{~min}$, and rinsed twice in sterile PBS. Subsequently, $3 \mathrm{mg} / \mathrm{ml}$ collagenase D (Roche Applied Science, Indianapolis, IN, USA) in culture medium was added for 3.5-4.5 h until the majority of the chondrocytes were visible. The digested cartilage was collected and centrifuged at $600 \mathrm{x}$ g for $5 \mathrm{~min}$ at $4^{\circ} \mathrm{C}$. The pellet was resuspended in Dulbecco's modified Eagle's medium (DMEM) and filtered to remove the undigested cartilage through 70-mm nylon mesh. Finally, the chondrocyte cells were plated in a new Petri dish with DMEM containing $10 \%$ fetal bovine serum (FBS; Gibco; Thermo Fisher Scientific, Inc., Waltham, MA, USA) and $1 \%$ antibiotics at $37^{\circ} \mathrm{C}$ in a $5 \% \mathrm{CO}_{2}$ incubator.

For the induction of inflammation and apoptosis in the cultured chondrocytes, LPS (200 $\mu \mathrm{g} / 100 \mu \mathrm{l}$, Escherichia coli, 055:B5, Sigma-Aldrich; Merck KGaA, Darmstadt, Germany) was used to treat the cells $\left(2 \times 10^{5} /\right.$ well $)$ at a final concentration of $5 \mu \mathrm{g} / \mathrm{ml}$ for $6 \mathrm{~h}$ at $37^{\circ} \mathrm{C}$ in a $5 \% \mathrm{CO}_{2}$ incubator.

Establishment of the OA model. The OA model was induced by medial meniscectomy tear (MMT) surgery as previously reported (14). The mice were anesthetized with an intraperitoneal injection of sodium pentobarbital $(100 \mathrm{mg} / \mathrm{kg})$, following which the mice were subjected to the MMT procedure. At
2 weeks post-surgery, the articular cartilages of the medial tibial plateau were collected and stored at $-80^{\circ} \mathrm{C}$ for subsequent analysis.

miRNA microarray. Total RNAs were isolated from the articular cartilage tissues using the miRNeasy mini kit (Qiagen UK, Crawley, UK) according to the manufacturer's protocol. Following quantification and quality assurance with a NanoDrop ND-1000 spectrophotometer (Thermo Fisher Scientific, Inc., Waltham, MA, USA) and an Agilent 2100 Bioanalyzer, duplicate samples were dephosphorylated and labeled using the miRCURY ${ }^{\mathrm{TM}} \mathrm{Hy} 3^{\mathrm{TM}} / \mathrm{Hy} 5^{\mathrm{TM}}$ Power labeling kit (Exiqon; Qiagen AB, Sollentuna, Sweden) and were then hybridized on the miRCURY ${ }^{\mathrm{TM}}$ LNA Array (v.16.0; Exiqon; Qiagen AB) according to the manufacturer's protocol. The procedure and image process method were as described previously (15).

Reverse transcription-quantitative polymerase chain reaction $(R T-q P C R)$ validation. Total RNAs were isolated from the articularcartilage tissues and articularchondrocytes using TRIzol reagent (Invitrogen; Thermo Fisher Scientific, Inc.) and reverse transcribed into cDNA with a TaqMan MicroRNA Reverse Transcription kit (Applied Biosystems; Thermo Fisher Scientific, Inc.) according to the manufacturer's protocol. To quantify TLR4 mRNA, $1 \mathrm{mg}$ of total RNA was reverse-transcribed into cDNA using the Oligo dT primer (Takara Biotechnology Co., Ltd., Dalian, China). qPCR analysis was performed using the TaqMan miRNAs Quantitation kit (Applied Biosystems, Foster City, CA, USA) on an Applied Biosystems 7300 real-time PCR system (Applied Biosystems; Thermo Fisher Scientific, Inc.). PCR reaction system was composed of $10 \mu \mathrm{l}$ RT-qPCR-Mix, $0.5 \mu \mathrm{l}$ upstream primer, $0.5 \mu \mathrm{l}$ downstream primer, $2 \mu \mathrm{l}$ cDNA

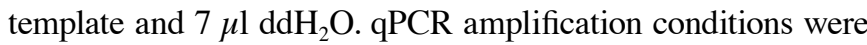
as follows: Initial denaturation at $95^{\circ} \mathrm{C}$ for $10 \mathrm{~min}, 40$ cycles of $95^{\circ} \mathrm{C}$ for $1 \mathrm{~min}$, and annealing at $60^{\circ} \mathrm{C}$ for $30 \mathrm{sec}$. The following primers were used: miR-93 forward, 5'-AGGCCC AAAGTGCTGTTCGT-3' and reverse, 5'-GTGCAGGGT CCGAGGT-3'; TLR4 forward, 5'-AGTTGATCTACCAAG CCTTGAGT-3' and reverse, 5'-GCTGGTTGTCCCAAAATC ACTTT-3'; Collagen type XI $\alpha 2$ (Col11a2) forward, 5'-CCT GGACCCCTTGGAAAG-3' and reverse, 5'-TCCCCCTTA GCTCCCTTCT-3'; Col2al forward, 5'-ACCCCCAGGTGC TAATGG-3' and reverse, 5'-GAACACCTTTGGGACCAT CTT-3'; Aggrecan (Acan) forward, 5'-GCCCTTCACGTG TAAAAAGG-3' and reverse, 5'-CAGGGAGCTGATCTC GTAGC-3'; U6 forward, 5'-GCTTCGGCAGCACATATA CTAAAAT-3' and reverse, 5'-CGCTTCACGAATTTG CGTGTCAT-3'; Glyceraldehyde phosphate dehydrogenase (GAPDH) forward, 5'-CTGGGCTACACTGAGCACC-3' and reverse, 5'-AAGTGGTCGTTGAGGGCAATG-3'. The relative expression of miR-93 was normalized with U6 and the relative expression of TLR4, Col11a2, Col2a1 and Acan were normalized with GAPDH. All reactions were performed in triplicate. The relative expression was calculated using the $2^{-\Delta \Delta c q}$ method (16).

Transfection. The miR-93 mimics, mimics negative control (mimics NC), miR-93 inhibitor and inhibitor NC were synthesized from GenePharma (Shanghai, China). To overexpress TLR4 in chondrocytes, the open reading frame region 
of human TLR4 gene was amplified and inserted into the pcDNA3.1 eukaryotic expression vector (Invitrogen; Thermo Fisher Scientific, Inc.). Lipofectamine 2000 was used for transfection according to the protocol of the manufacturer until the chondrocytes reached $30-50 \%$ confluence.

Cell viability assay. Cell viability was determined using an MTT assay to detect the effect of miR-93 on chondrocyte viability following LPS treatment. At $48 \mathrm{~h}$ post-transfection, $25 \mu \mathrm{l}$ of MTT (Sigma; Merck KGaA) was added into each well $\left(2 \times 10^{5} /\right.$ well $)$ and the cells were incubated for another $4 \mathrm{~h}$ at $37^{\circ} \mathrm{C}$. The OD absorbance at $450 \mathrm{~nm}$ was measured using a microplate reader (Infinite M200; Tecan Group, Ltd., Mannedorf, Switzerland). All experiments were performed in triplicate.

Detection of apoptosis by flow cytometry. Following transfection for $48 \mathrm{~h}$, cell apoptosis was measured using an Annexin V-FITC Apoptosis Detection kit (BD Biosciences, San Diego, CA, USA) according to the manufacturer's protocol. The cells and their supernatants were harvested and washed twice with PBS. Annexin V was added to the suspended cells and incubated at $4^{\circ} \mathrm{C}$ for $15 \mathrm{~min}$ in the dark. Propidium iodide was then added for incubation for $5 \mathrm{~min}$ in the dark. The stained cells were analyzed using a flow cytometer (FACSCalibur; BD Biosciences).

Enzyme-linked immunosorbent assay (ELISA). To determine the release of inflammatory cytokines, the levels of TNF- $\alpha$, IL- $1 \beta$, and IL- 6 in the supernatants of chondrocytes transfected with miRNA oligonucleotides or pcDNA-TLR4 were detected using the Valukine ELISA kit (R\&D Systems, Inc., Minneapolis, MN, USA) according to the manufacturer's protocol.

Terminal deoxynucleotidyl transferase-mediated dUTP-biotin nick-end labeling (TUNEL) staining. The articular cartilage tissues (10-mm thickness) obtained in the above experimental procedure were subjected to TUNEL staining. Following deparaffinization with xylene, the sections of articular cartilage tissues were rehydrated with ethanol at graded concentrations of 100-70\% (v/v), followed by washing with water. Subsequently, the tissues sections were subjected to $100 \mu \mathrm{l}$ proteinase K $(20 \mu \mathrm{g} / \mathrm{ml}$; Roche Diagnostics, Basel, Switzerland) for $15 \mathrm{~min}$ at room temperature, and then washed three times with PBS. TUNEL solution preparation and staining were performed using a TUNEL Apoptosis Detection kit (Alexa Fluor 488; Roche Diagnostics). Cell quantification was performed using an inverted fluorescence microscope (DP73; Olympus Corporation, Tokyo, Japan) at x400 magnification. The TUNEL-positive cells were counted in three fields of view per section.

$N F-\kappa B$ activity assay. The chondrocytes were plated in 6-well tissue culture plates at a concentration of $5 \times 10^{4}$ cells/ well for $24 \mathrm{~h}$. The cells were then transfected with $2.5 \mu \mathrm{g}$ of a $\mathrm{NF}-\kappa \mathrm{B}$ reporter luciferase construct. After $6 \mathrm{~h}$, the cells were washed and then co-transfected with miR-93 mimics and pcDNA-TLR4 for $24 \mathrm{~h}$. The cells were then washed in PBS and harvested in $500 \mu 1 \mathrm{lX}$ passive lysis buffer. Luciferase activity was quantified using a Promega luciferase assay kit on a luminometer. The experimental values were recorded relative to those of untreated control samples.

Dual-luciferase reporter assays. The predicted and mutated sequences targeting the 3'UTR of TLR4 were amplified and cloned into the pGL3 vector (Promega Corporation, Madison, WI, USA). pGL3-TLR4-3'UTR wild-type (Wt) and pGL3-TLR4-3'UTR mutated (Mut) were synthesized by GenePharma. 293 cells (American Type Culture Collection, Manassas, VA, USA) were seeded into 24-well plates at a density of $1-2 \times 10^{5}$ cells per well, and co-transfected with $20 \mathrm{nM}$ miR-93 mimics, $20 \mathrm{nM}$ miR-93 inhibitor, or $20 \mathrm{nM}$ miR-NC and $0.2 \mu \mathrm{g}$ pGL3-TLR4-3'UTR Wt or $0.2 \mu \mathrm{g}$ pGL3-TLR4-3'UTR Mut using Lipofectamine 2000 (Invitrogen; Thermo Fisher Scientific, Inc.). The 293 cells were collected $48 \mathrm{~h}$ following transfection and analyzed using the Dual-Luciferase Reporter Assay system (Promega Corporation) The pRL-TK vector was used as an internal control. All experiments were performed in triplicate and repeated three times.

Western blot analysis. Protein samples from the tissues and cells were prepared with lysis buffer and protease inhibitor (Roche Diagnostics). The protein concentration was determined using a bicinchoninic acid assay kit (Beyotime Institute of Biotechnology, Haimen, China). The proteins (30 $\mu \mathrm{g}$ each sample) were resolved on $10 \%$ SDS-PAGE gels, transferred onto PVDF membranes (EMD Millipore, Billerica, MA, USA). Following blocking with Tris-buffered saline and Tween (TBST) containing 5\% skim milk, the membranes were incubated overnight at $4{ }^{\circ} \mathrm{C}$ with primary antibodies against TLR4 (cat. no. 14358; 1:2,000), nuclear phosphorylated (p)-p65

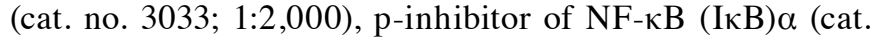
no. $14358 ; 1: 2,000) \beta$-actin (cat. no. 4970; 1:2,000) and Histone H3 (cat. no. 9728; 1:2,000; all from Cell Signaling Technology, Inc., Danvers, MA, USA). Detection was performed by incubation with peroxidase-conjugated secondary antibodies (cat. no. ab6734; 1:2,000; Abcam, Cambridge, UK) and chemiluminescence (EMD Millipore) for $1 \mathrm{~h}$ at room temperature. Densitometric analysis was performed using Quantity One software (v4.62; Bio-Rad Laboratories, Inc., Hercules, CA, USA). $\beta$-actin protein was used as the inner control of the cytoplasmic proteins; Histone $\mathrm{H} 3$ protein was used as the inner control of the nuclear proteins. Each experiment was run in triplicate.

Statistical analysis. Statistical analysis was performed using SPSS 15.0 (SPSS, Inc., Chicago, IL, USA). Quantitative data are presented as the mean \pm standard deviation. The comparison between data was calculated using Student's t-test and one-way analysis of variance followed by Tukey's post hoc test. $\mathrm{P}<0.05$ was considered to indicate a statistically significant difference.

\section{Results}

Aberrant expression of miRNAs in the articular cartilages of OA mice. To investigate the potential involvement of miRNAs following OA, microarray analysis was performed to determine miRNA levels in the articular cartilages ( $n=2 /$ group). In the miRNA microarray analysis, 16 miRNAs were upregulated and 
A

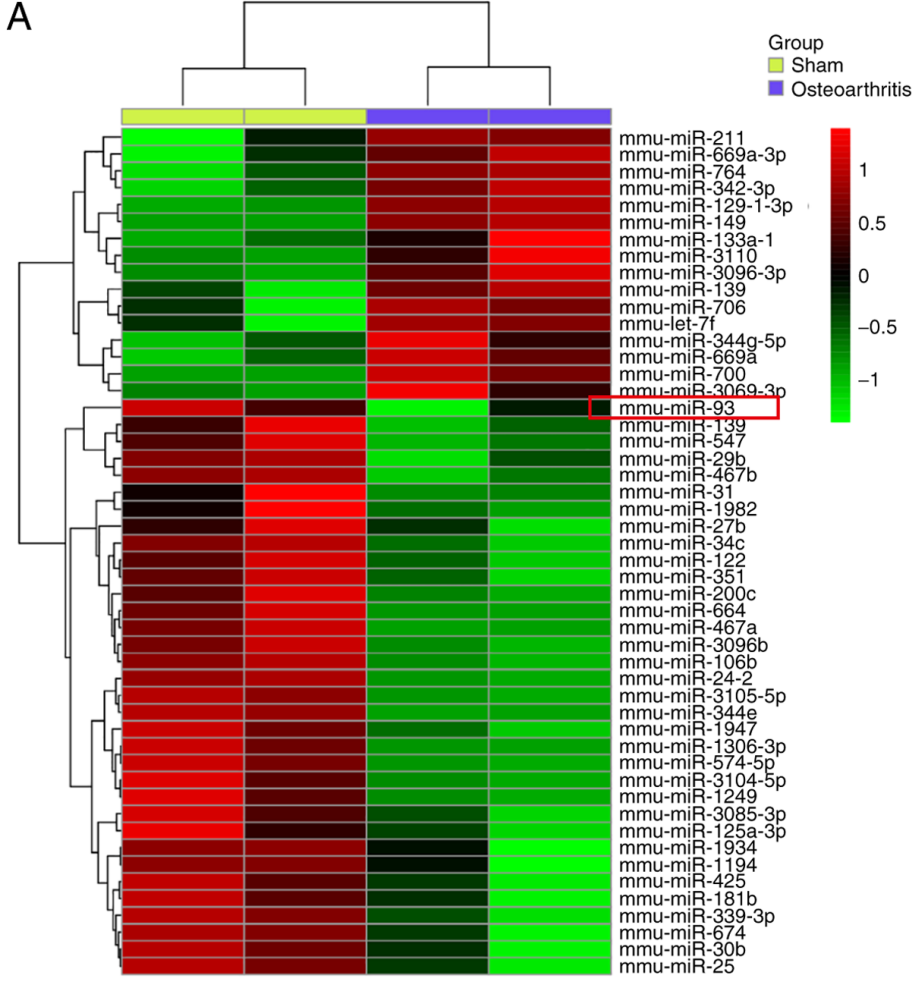

B
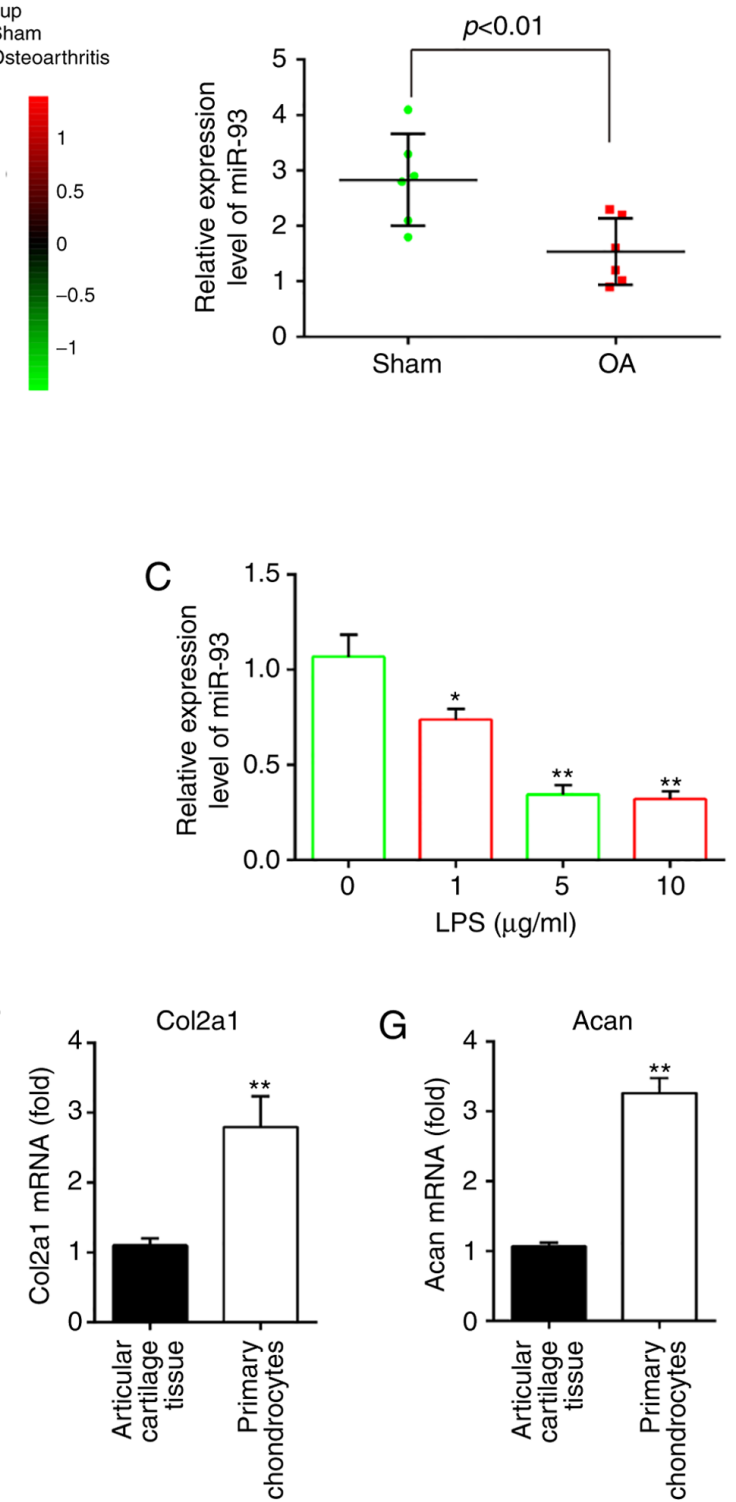

G

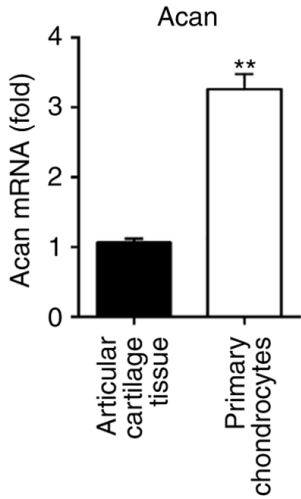

Figure 1. miR-93 is downregulated in OA mice and LPS-treated chondrocytes. (A) Mice were randomly divided into two groups, the sham group and OA group ( $\mathrm{n}=2$ /group). The heat map of miRNA profiles in the articular cartilages shows the significantly dysregulated miRNAs. The color code in the heat maps is linear, with green as the lowest and red as the highest. Upregulated miRNAs are shown in red, whereas downregulated miRNAs are shown in green. (B) Expression of miR-93 was validated by RT-qPCR analysis in OA mice $(n=6) . P<0.01$, vs. Sham group. (C) Chondrocytes were stimulated with an increasing concentration gradient of LPS $(0,1,5$, and $10 \mu \mathrm{g} / \mathrm{ml})$ for $6 \mathrm{~h}$, and the expression of miR-93 was measured by RT-qPCR analysis. Data are presented as the mean \pm standard deviation of three independent experiments. ${ }^{*} \mathrm{P}<0.05,{ }^{* * *} \mathrm{P}<0.01$, vs. untreated group. (D) Image of primary chondrocytes cultured for 7 days (magnification, x100). Expression of chondrocyte markers (E) Col11a2, (F) Col2a1 and (G) Acan in articular cartilage tissues and mouse primary chondrocytes were measured by RT-qPCR analysis. Data are presented as the mean \pm standard deviation of three independent experiments. ${ }^{* *} \mathrm{P}<0.01$, vs. articular cartilage tissues. OA, osteoarthritis; miRNA/miR, microRNA, LPS, lipopolysaccharide; RT-qPCR, reverse transcription-quantitative polymerase chain reaction; Col11a2, collagen type XI $\alpha 2$; Col2a1, collagen, type II, $\alpha 1$; chain; Acan, aggrecan.

34 miRNAs were downregulated in the OA group compared with the sham group (Fig. 1A). Among aberrant miRNAs, miR-93 was one of the most significantly downregulated in the articular cartilages of OA mice based on the microarray expression data, and multiple studies have shown that miR-93 has anti-apoptotic and anti-inflammatory effects in several types of cells (17-19). Therefore, miR-93 was selected for further investigation. The expression of miR-93 was validated using RT-qPCR analysis and was shown to be significantly lower in the OA group than in the sham group (Fig. 1B).

As the in vitro model of LPS-treated chondrocytes is often used in OA investigations $(20,21)$, the present study investigated the functions of miR-93 in the development of OA using this cell model. The expression of miR-93 was first examined in the LPS-induced OA cell model. Consistent with the findings from analyzing the expression of miR-93 in the articular cartilages, the expression of miR-93 was found to be markedly decreased by LPS treatment, and the levels of miR-93 levels were downregulated in a dose-dependent manner (Fig. 1C). No significant difference in the level of miR-93 was found between 5 and $10 \mu \mathrm{g} / \mathrm{ml}$, therefore LPS at a dose of $5 \mu \mathrm{g} / \mathrm{ml}$ was used for subsequent experiments, which has been used in a previous study (22). The data suggested that miR-93 may be important in the development of OA. 
A

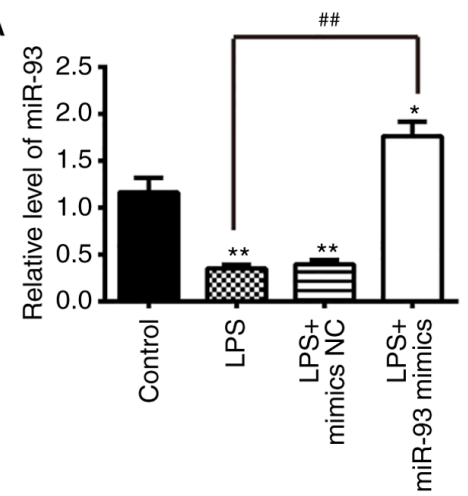

B

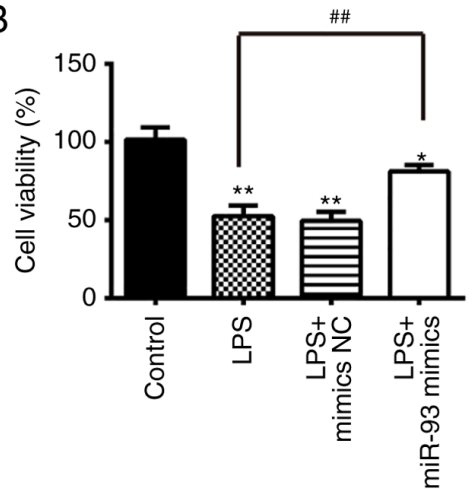

$\mathrm{D}$

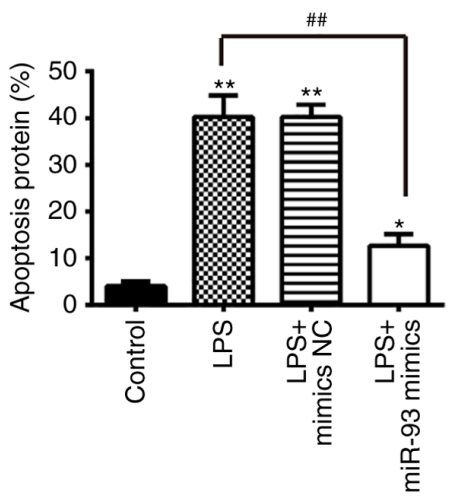

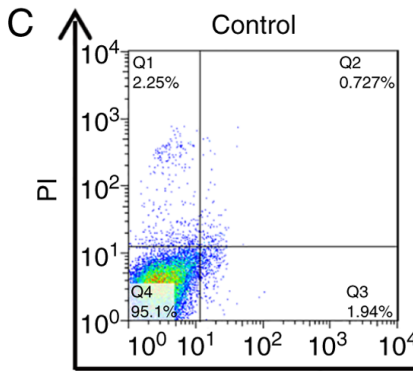
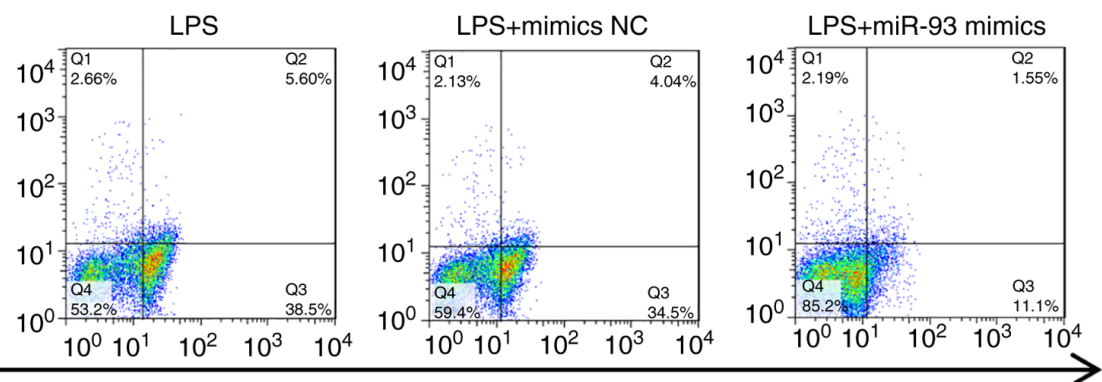

Annexin V-FITC
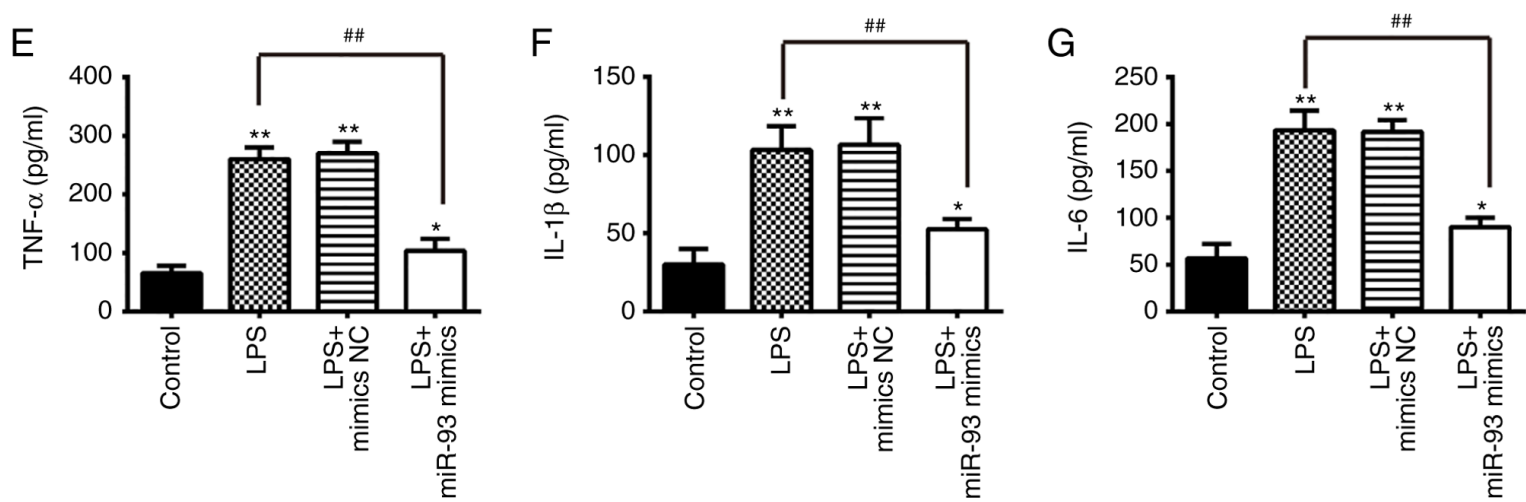

Figure 2. Overexpression of miR-93 suppresses apoptosis and inflammation in LPS-treated chondrocytes. Chondrocytes were transfected with miR-93 mimics or miR-NC for $24 \mathrm{~h}$ and then treated with LPS $(5 \mu \mathrm{g} / \mathrm{ml})$ for $24 \mathrm{~h}$. The cells and cell supernatants were used for further analysis. (A) Expression levels of miR-93 were assessed by reverse transcription-quantitative polymerase chain reaction analysis. (B) Cell viability was measured using an MTT assay. (C) Apoptosis was detected by flow cytometry and (D) quantification. The levels of (E) TNF- $\alpha$, (F) IL-1 $\beta$, and (G) IL-6 were measured using enzyme-linked immunosorbent assay kits. Data are presented as the mean \pm standard deviation of three independent experiments. ${ }^{*} \mathrm{P}<0.05,{ }^{* * *} \mathrm{P}<0.01$, vs. control group. ${ }^{\# \#} \mathrm{P}<0.01$, vs. miR-NC; LPS alone group. miR, microRNA; LPS, lipopolysaccharide; NC, negative control; TNF- $\alpha$, tumor necrosis factor; IL, interleukin; PI, propidium iodide.

After 4 days, the primary mouse articular chondrocytes began to appear spread out in the tissue and the cells reached confluence $\sim 7$ days later. The cultured primary mouse articular chondrocytes were spindle-shaped with a fibroblast-like appearance (Fig. 1D). They were characterized by the absence of chondrocyte markers, including Col11a2, Col2a1 and Acan. The results of the RT-qPCR analysis showed that the levels of these chondrocyte markers were higher in the mouse primary chondrocytes than that in the articular cartilage tissues, indicating that chondrocytes do not lose their characteristics (Fig. 1E-G).

miR-93 inhibits LPS-induced apoptosis and inflammatory cytokine production. To further investigate the role of miR-93 in OA, chondrocytes were transfected with miR-93 mimics for $24 \mathrm{~h}$, and then treated with $5 \mu \mathrm{g} / \mathrm{ml}$ LPS for another $24 \mathrm{~h}$. The miRNA transfection efficiency was first evaluated via the RT-qPCR assay. The frequent downregulation of miR-93 in the articular cartilages of OA mice suggests that miR-93 may be important in the progression of OA. The biological consequences of the overexpression of miR-93 in regulating apoptosis and the inflammatory response were then examined using cell biology assays. The expression of miR-93 was significantly increased in chondrocytes transfected with miR-93 mimics, followed by treatment with LPS (Fig. 2A). Subsequently, cell viability, apoptosis and inflammatory cytokine production were assessed using MTT, flow cytometry and ELISA, respectively. The results showed that LPS treatment significantly decreased the cell viability and induced cell apoptosis compared with the control group, whereas these effects were inhibited following miR-93 mimics transfection. (Fig. 2B-D). The effect of the overexpression of miR-93 on the release of pro-inflammatory cytokines that contribute to the clinical symptoms of OA was further assayed (23). The 
A Mouse TLR4 ENST00000355622.6 3' UTR length: 6389

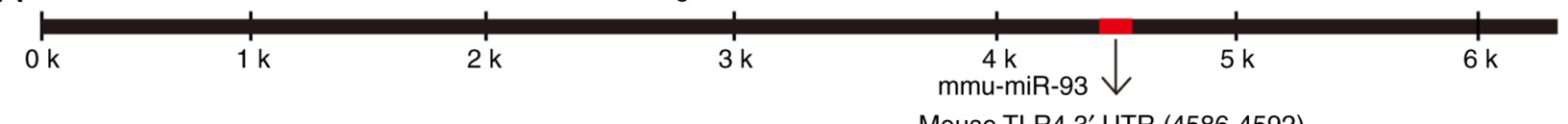

B Position 4586-4592 of TLR4 3'-UTR

wt TLR4 3'-UTR: $5^{\prime}$... UACUACUUGCAAAAA--GCACUUUU... 3' II II IIIIIII

mmu-miR-93: 3' ...GAUGGACGUGCUUGUCGUGAAAC... 5'

mut TLR4 3'-UTR: 5' ...UACUACUUGCAAAAA--AUCGAGCU... 3'

Mouse TLR4 3' UTR (4586-4592)

C

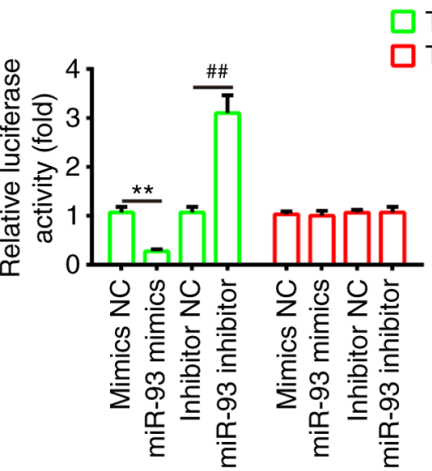

TLR4 3'-UTR wt

TLR4 3'-UTR mut
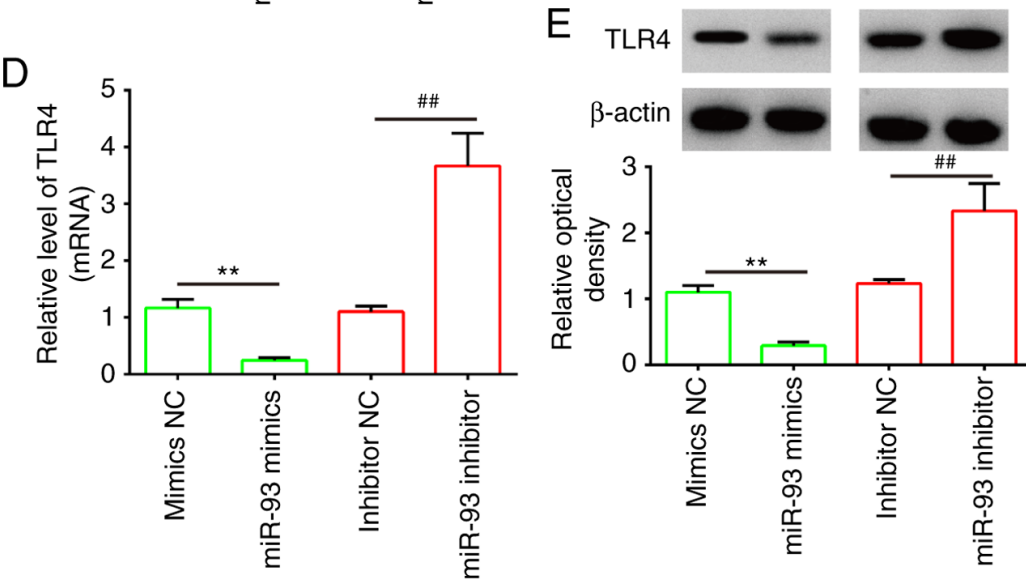

\begin{tabular}{|c|c|}
\hline & 4600. \\
\hline Mouse & --AAA GCAC-UUU GAAAUAAGCUGUGG- \\
\hline Human & --AGA-GCAC-UUU|GAAAUUAAUGGCAG- \\
\hline Chimp & --AGA GCAC-UUUU GAAAUUAAUGGCAG- \\
\hline Rhesus & --AGA-GGAC-UUUUGAAAUUAACGGCAG- \\
\hline Squirrel & --AGA-ACAC-UUUUGAAAUUGGCUGCAG- \\
\hline Rat & --AAA-GCAC-UUU GAAAUGAACUGUGG- \\
\hline Rabbit & -GAAAUUAACAUCAC \\
\hline Pig & --AGA-GCAG-UUUUUUAAAUUAAUGGCAG- \\
\hline Cow & --GGA-GCAG-UUUUUGAGAUUAAAUGCCL \\
\hline Cat & --AGA GCAC-UUUTGAAAUUCAUGGCA \\
\hline Dog & --AGA GCAC-UUUU] GAAAUUUAUGGCAC \\
\hline & -AUA-GCAC-CUULGAAAUGAACGGCA \\
\hline & \\
\hline Macaw & \\
\hline Chicken & \\
\hline opical & \\
\hline
\end{tabular}

Figure 3. TLR4 is a direct target of miR-93. (A) Putative binding site of miR-93 and TLR4. (B) Mutation was generated on the TLR4 3'UTR sequence in the complementary site for the seed region of miR-93. TLR4 3'UTR fragments containing the wild-type or mutant miR-93-binding sequence were cloned downstream of the luciferase reporter gene in pGL3-luc vector. (C) Luciferase assay of 293 cells co-transfected with firefly luciferase constructs containing TLR4 wt or mut 3'-UTRs and miR-93 mimics, mimics NC, miR-93 inhibitor or inhibitor NC, as indicated $(n=3)$. Data are presented as the mean \pm standard deviation of three independent experiments. ${ }^{* *} \mathrm{P}<0.01$, vs mimics NC, ${ }^{\# \#} \mathrm{P}<0.01$, vs inhibitor NC. (D) mRNA and (E) protein expression of TLR4 following transfection with miR-93 mimics or miR-93 inhibitor was measured by RT-qPCR and western blot analyses. Data are presented as the mean \pm standard deviation of three independent experiments. ${ }^{* *} \mathrm{P}<0.01$, vs, inhibitor NC, ${ }^{\# \#} \mathrm{P}<0.01$, vs mimics NC. (F) Chondrocytes were transfected with miR-93 mimics or miR-93 inhibitor for $24 \mathrm{~h}$ and then treated with LPS $(5 \mu \mathrm{g} / \mathrm{ml})$ for $24 \mathrm{~h}$. Expression of TLR4 was assessed by RT-qPCR analysis. Data are presented as the mean \pm standard deviation of three independent experiments. ${ }^{*} \mathrm{P}<0.05,{ }^{* *} \mathrm{P}<0.01$, vs. control group; ${ }^{\# \#} \mathrm{P}<0.01$, vs. LPS + mimics NC group; ${ }^{\& \&} \mathrm{P}<0.01$, vs. LPS + inhibitor NC group. TLR4, Toll-like receptor 4; miR, microRNA; UTR, untranslated region; wt, wild-type; mut, mutant; NC, negative control; LPS, lipopolysaccharide; RT-qPCR, reverse transcription-quantitative polymerase chain reaction.

protein levels of cytokines, including TNF- $\alpha$, IL-1 $\beta$ and IL-6, in chondrocytes overexpressing miR-93 following LPS stimulation was measured by ELISA. The upregulation of miR-93 suppressed the LPS-induced expression of pro-inflammatory cytokines, compared with chondrocytes transfected with the mimics NC (Fig. 2E-G). These results indicated that miR-93 protected the chondrocytes from LPS-induced apoptosis and inflammation.

TLR4 is a direct target of miR-93. To investigate the potential molecular mechanism of miR-93, the potential targets of miR-93 were predicted by bioinformatics analysis. It was found that the 3'-UTR of TLR4, an important regulator of the NF- $\mathrm{KB}$ pathway, possesses sequences complementary to the miR-93 seed sequence (Fig. 3A and B). To verify whether miR-93 is directly bound to TLR4, a dual luciferase reporter assay was performed. It was observed that the overexpression of miR-93 decreased relative luciferase activity in the presence of the Wt 3'-UTR, whereas the knockdown of miR-93 increased the relative luciferase activity. Similarly, no significant change in luciferase activity was observed when the targeted sequence of TLR4 was mutated in the miR-93-binding site (Fig. 3C). To further confirm that TLR4 was negatively regulated by miR-93, the of mRNA and protein expression levels of TLR4 were analyzed by RT-qPCR and western blot analyses. The expression of TLR4 at the mRNA and protein levels was significantly 
A

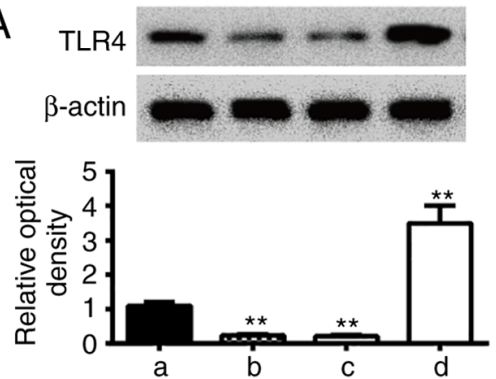

B

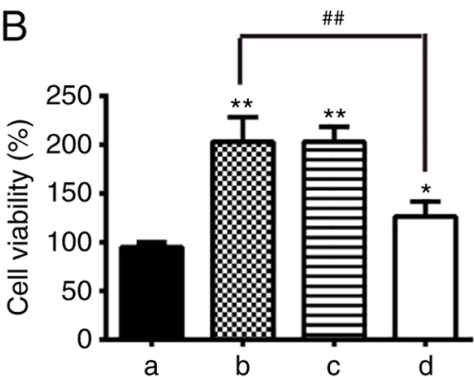

C

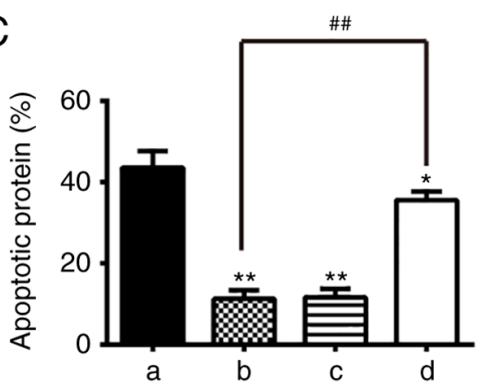

$\mathrm{D} \uparrow$

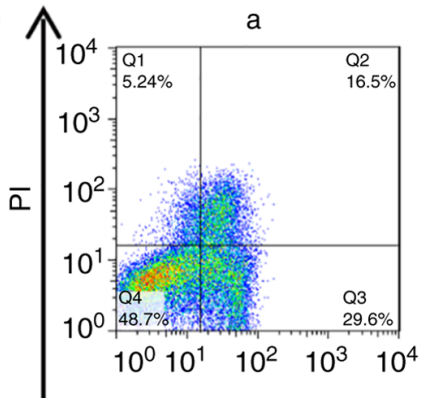

b

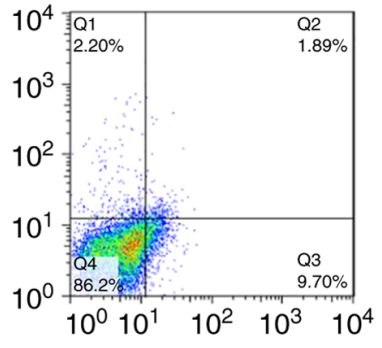

C

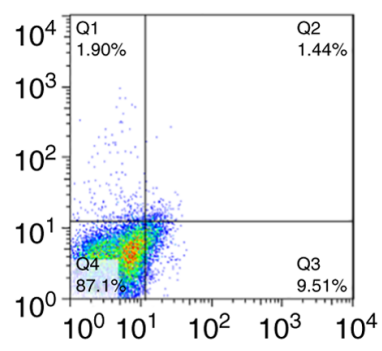

d

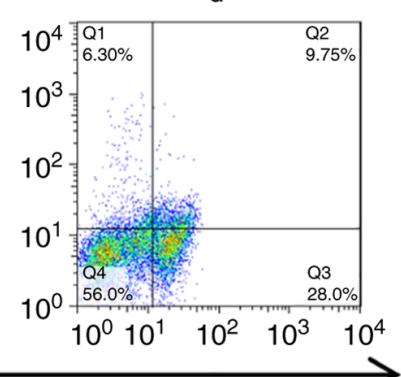

Annexin V-FITC
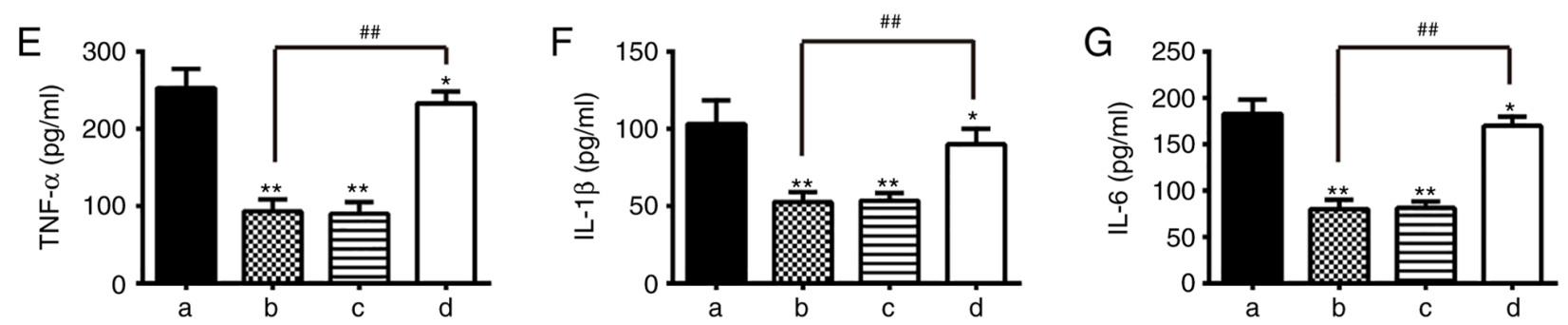

a: LPS

b: LPS+miR-93 mimics c: LPS+miR-93 mimics+pcDNA-vector d: LPS+miR-93 mimics+pcDNA-TLR4

Figure 4. Overexpression of TLR4 abrogates the inhibitory effects of miR-93 mimics on inflammation and apoptosis. Chondrocytes were co-transfected with miR-93 mimics and pcDNA-TLR4 for $24 \mathrm{~h}$ and then exposed to $5 \mu \mathrm{g} / \mathrm{ml}$ LPS for $24 \mathrm{~h}$. The cells and cell supernatants were used for further analysis. (A) Protein levels of TLR4 were detected by western blot analysis. (B) Cell viability was measured using an MTT assay. Apoptosis was (C) quantified following (D) detection by flow cytometry. Levels of (E) TNF- $\alpha,(F)$ IL-1 $\beta$, and (G) IL-6 were measured using ELISA kits. Data are presented as the mean \pm standard deviation of three independent experiments. ${ }^{*} \mathrm{P}<0.05,{ }^{* *} \mathrm{P}<0.01$, vs. LPS alone group, ${ }^{\# \prime} \mathrm{P}<0.01$, vs. LPS + miR-93 mimics group. TLR4, Toll-like receptor 4 ; miR, microRNA; LPS, lipopolysaccharide; TNF, tumor necrosis factor; IL, interleukin; PI, propidium iodide.

downregulated following the overexpression of miR-93 in chondrocytes, but upregulated following miR-93 knockdown (Fig. 3D and E). In addition, using an OA cell model, it was found that LPS treatment increased the mRNA levels of TLR4 and this promoting effect was reversed by transfection with the miR-93 mimics. By contrast, the miR-93 inhibitor enhanced the promoting effect of LPS on the mRNA levels of TLR4, suggesting that miR-93 also negatively regulated the expression of TLR4 in the LPS-induced chondrocytes (Fig. 3F). As TLR4/NF- $\kappa \mathrm{B}$ signaling is associated with inflammation in OA, miR-93 may exert its protective effects on LPS-induced injury by targeting TLR4.

miR-93 inhibits LPS-induced apoptosis and inflammation through TLR4 in chondrocytes. To ascertain whether TLR4 is involved in miR-93 inhibiting the LPS-induced inflammatory response and apoptosis of chondrocytes, the chondrocytes were transfected with miR-93 mimics and pcDNA-TLR4 in addition to LPS stimulation. A western blot assay was used to assess the transfection efficiency. The protein expression level of TLR4 was significantly increased in the LPS-treated chondrocytes following pcDNA-TLR4 transfection (Fig. 4A). Subsequently, the viability, apoptosis and the levels of pro-inflammatory cytokines were assessed by MTT, flow cytometry and ELISA, respectively. As shown in Fig. 4B, overexpression of TLR4 significantly reduced the viability of the chondrocytes transfected with miR-93 mimics. In addition, the cell apoptosis and the production of pro-inflammatory cytokines (TNF- $\alpha$, IL-1 $\beta$ and IL-6) reduced by the miR-93 mimics were reversed by the overexpression of TLR4 (Fig. 4B-G). Taken together, these data suggested that miR-93 suppressed LPS-stimulated apoptosis and pro-inflammatory cytokine production through targeting TLR4.

miR-93 inhibits activation of the TLR4/NF- $\kappa B$ pathway in LPS-treated chondrocytes. Previous studies have shown that TLR4 can activate the NF- $\kappa$ B pathway, and thus result in the secretion of pro-inflammatory cytokines $(24,25)$. In the present study, it was found that the overexpression of miR-93 negatively influenced the expression of TLR4 in 

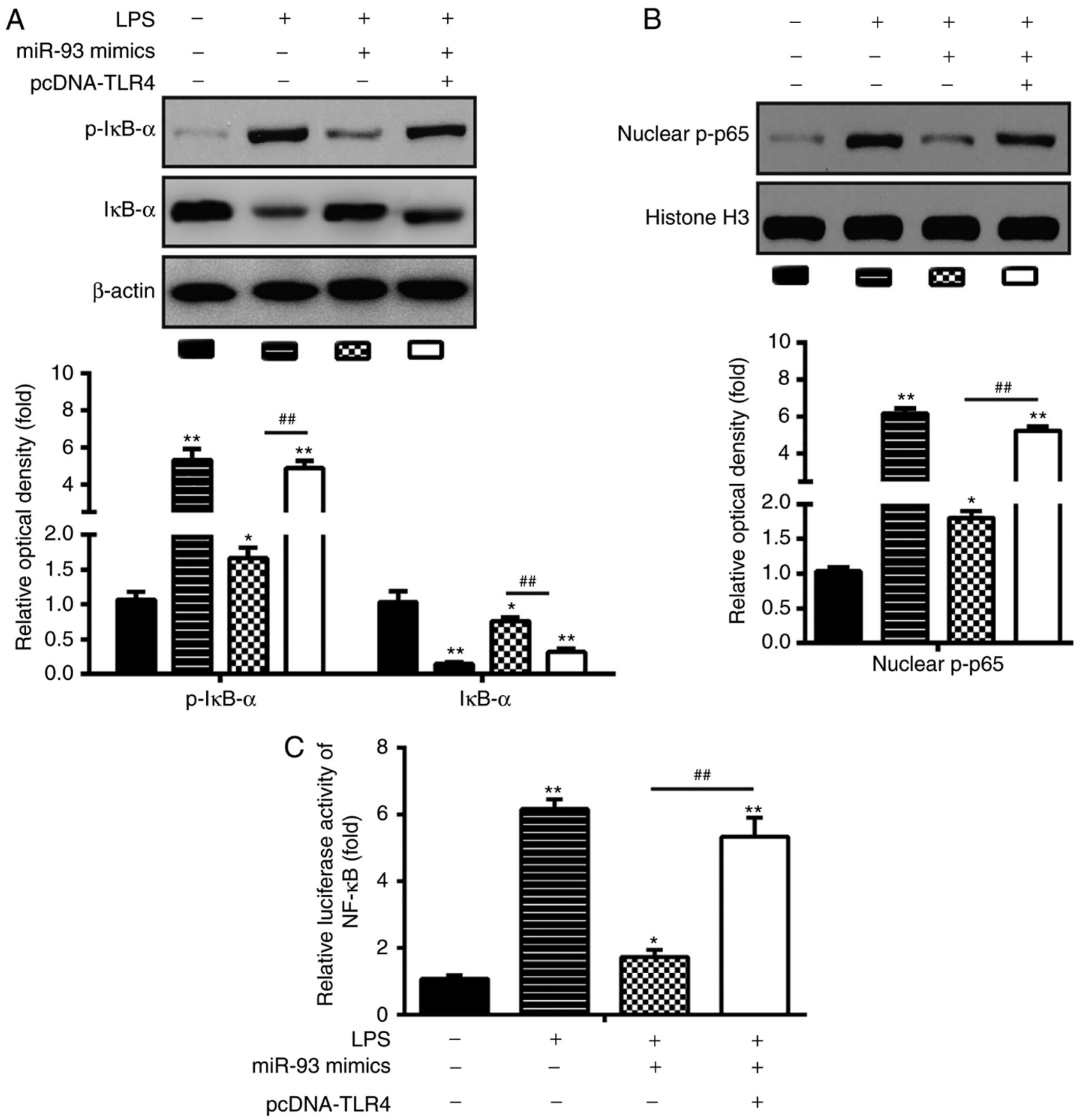

Figure 5. Overexpression of miR-93 inhibits the NF- $\mathrm{kB}$ pathway via targeting TLR4 in LPS-treated chondrocytes. Chondrocytes were co-transfected with miR-93 mimics or miR-NC for $24 \mathrm{~h}$ and then exposed to $5 \mu \mathrm{g} / \mathrm{ml}$ LPS for $24 \mathrm{~h}$. The cells were used for further analysis. (A) Levels of TLR4, nuclear p-p65 and p-IкB- $\alpha$ were measured by western blot analysis. (B) Bands were semi-quantitatively analyzed using ImageJ software. $\beta$-actin protein was used as the inner control of the cytoplasmic proteins; Histone $\mathrm{H} 3$ protein was used as the inner control of nuclear proteins. (C) NF- $\mathrm{kB}$ activity was assessed using the NF- $\mathrm{kB}$ activity assay. Data are presented as the mean \pm standard deviation of three independent experiments. ${ }^{*} \mathrm{P}<0.05,{ }^{* *} \mathrm{P}<0.01$, vs. control group; ${ }^{\sharp \#} \mathrm{P}<0.01$, vs. LPS

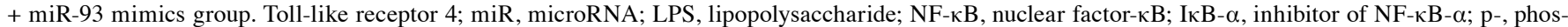
phorylated.

LPS-treated chondrocytes. Therefore, the effects of miR-93 on the LPS-induced expression of NF- $\kappa \mathrm{B}$ pathway-related core factors, nuclear p-p65 and p-IкB- $\alpha$ were TLR4. As shown in Fig. 5A and B, in LPS-induced chondrocytes, LPS promoted the activation of the NF- $\mathrm{KB}$ pathway through increasing the expression of nuclear p-p65 and reducing the expression of p-IкB- $\alpha$, which was inhibited by transfection with miR-93 mimics. However, the upregulation of TLR4 reactivated the NF- $\kappa B$ pathway inhibited the overexpression of miR-93. To confirm the inhibitory effect of miR-93 in the TLR4/NF-kB signaling pathway, the NF- $\mathrm{kB}$ activity assay was performed. As shown in Fig. 5C, the activity of NF- $\mathrm{KB}$ was reduced in the miR-93 mimics-transfected chondrocytes, however, this inhibitory effect was reversed by the overexpression of TLR4 (Fig. 5C). These data suggest that miR-93 inhibited activation of the TLR4/NF- $\kappa$ B pathway in the LPS-treated chondrocytes.

Agomir-93 improves apoptosis and inflammation in $O A$ mice. In order to confirm the functions of miR-93 in the development of OA in vivo, a mouse model of OA was injected with agomir-miR-93 (5 nmol) via intra-articular injection. The overexpression efficiency of agomir-miR-93 was evaluated using RT-qPCR analysis in the articular cartilage tissues ( $n=6 /$ group). As shown in Fig. 6A, the relative expression of miR-93 was significantly upregulated compared with that in the OA group. Subsequently, ELISA 
A

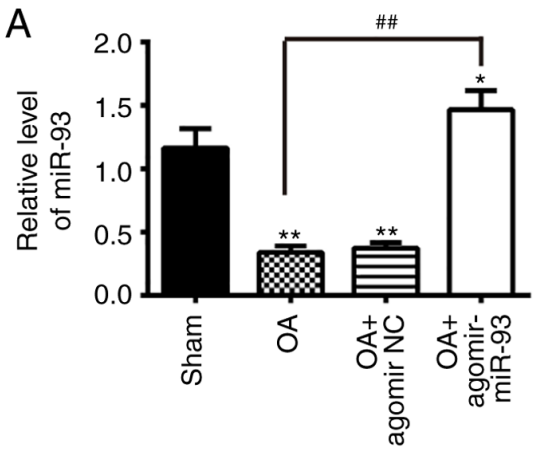

D

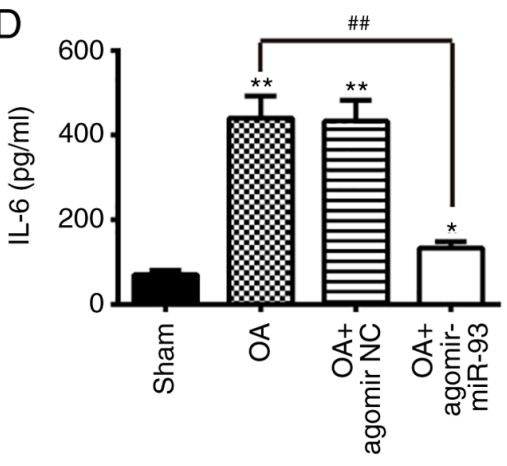

B

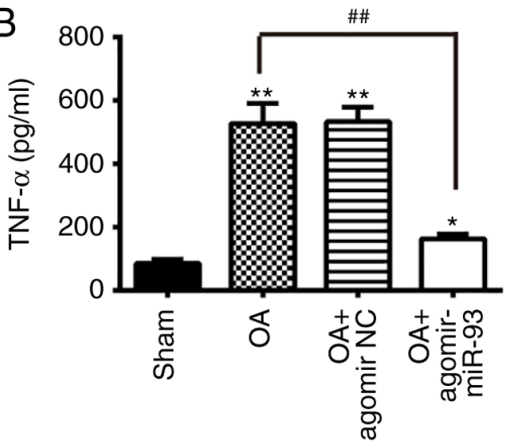

$\mathrm{E}$

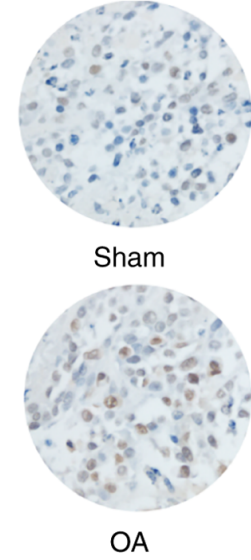

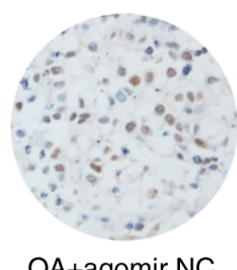

$\mathrm{OA}+$ agomir $\mathrm{NC}$

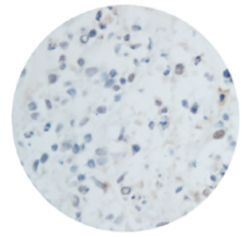

OA+agomir-miR-93
C

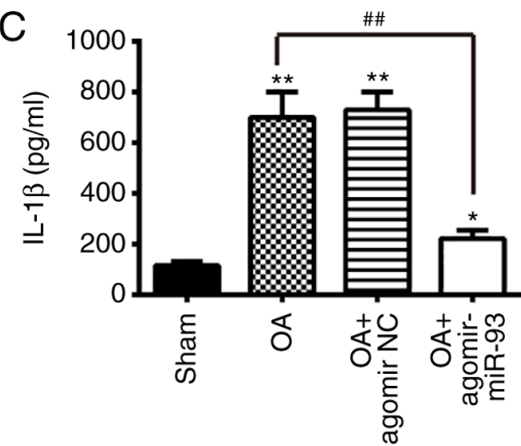

$\mathrm{F}$
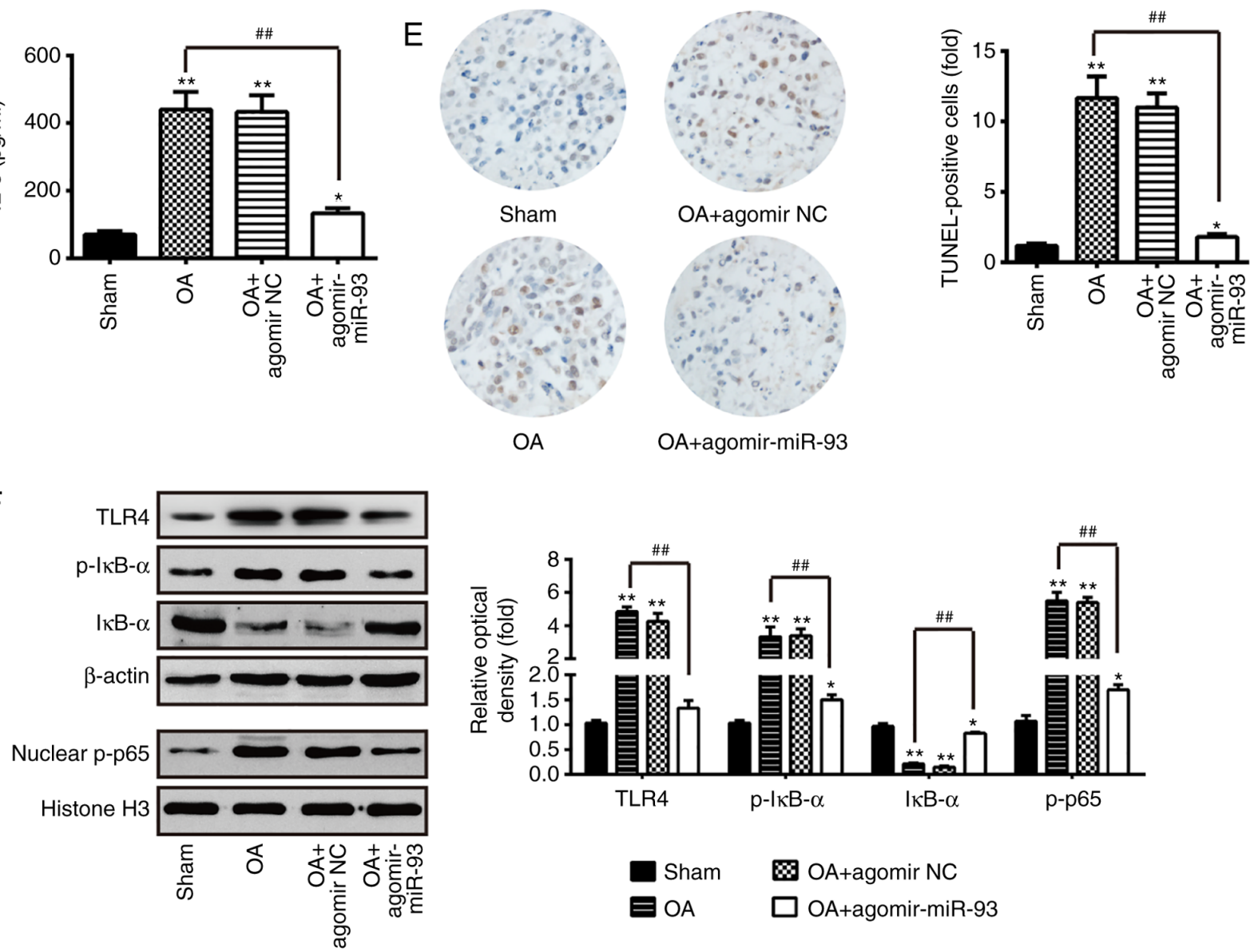

$\begin{array}{ll}\text { Sham } & \text { \# OA+agomir NC } \\ \text { E OA } & \square \text { OA+agomir-miR-93 }\end{array}$

Figure 6. miR-93 attenuates inflammation and apoptosis in OA mice. The mouse model of OA was injected with antagomir-miR-93 (5 nmol) via intra-articular injection. The mice were then subjected to medial meniscectomy tear surgery and treated with agomir-NC as the negative control. After 2 weeks, all mice were sacrificed. Subsequently, the articular cartilages of the medial tibial plateau and the synovial fluid were collected for further analysis. (A) Relative expression of miR-93 was determined by reverse transcription-quantitative polymerase chain reaction analysis. Release of (B) TNF- $\alpha$, (C) IL- $1 \beta$, and (D) IL-6 inflammatory cytokines were measured using ELISA kits. (E) Apoptotic cells were determined using TUNEL staining (magnification, x100). (F) Levels of TLR4, nuclear p-p65 and p-IкB- $\alpha$ were measured by western blot analysis. $\beta$-actin protein was used as the inner control of the cytoplasmic proteins; Histone H3 protein was used as the inner control of nuclear proteins. Data are presented as the mean \pm standard deviation of three independent experiments. $\mathrm{P}<0.05$, ${ }^{* *} \mathrm{P}<0.01$, vs. Sham group; ${ }^{\# \#} \mathrm{P}<0.01$, vs. OA group. Toll-like receptor 4; miR, microRNA; OA, osteoarthritis; NC, negative control; TNF, tumor necrosis factor; IL, interleukin; $\mathrm{NF}-\kappa \mathrm{B}$, nuclear factor- $\kappa \mathrm{B}$; I $\kappa \mathrm{B}-\alpha$, inhibitor of NF- $\kappa \mathrm{B}-\alpha$; p-, phosphorylated; TUNEL, terminal deoxynucleotidyl transferase-mediated dUTP-biotin nick-end labeling.

was performed to evaluate pro-inflammatory cytokine production in the OA mouse model following agomir-miR-93 injection. As shown in Fig. 6B-D, the upregulation of miR-93 in OA mice caused a significant reduction of TNF- $\alpha, \mathrm{IL}-1 \beta$ and IL-6. Furthermore, the effect of miR-93 on apoptotic cells in the OA mice was analyzed by TUNEL staining. It was found that, compared with the sham group, treatment with agomir-miR-93 significantly reduced the positive cells and certain TUNEL-positive cells were larger in size with dark-brown dots in the OA group (Fig. 6E). In addition, the expression of NF- $\mathrm{KB}$ pathway-related core factors were measured in vivo. As shown in Fig. 6F, the expression levels of TLR4 and nuclear p-p65 were increased, and p-IкB- $\alpha$ was decreased in OA mice compared with sham group, whereas the effects were reversed by the overexpression of miR-93 (Fig. 6F). These findings suggested that miR-93 inhibits apoptosis and inflammation by modulating the TLR4/NF- $\kappa \mathrm{B}$ signaling pathway in OA mice. 

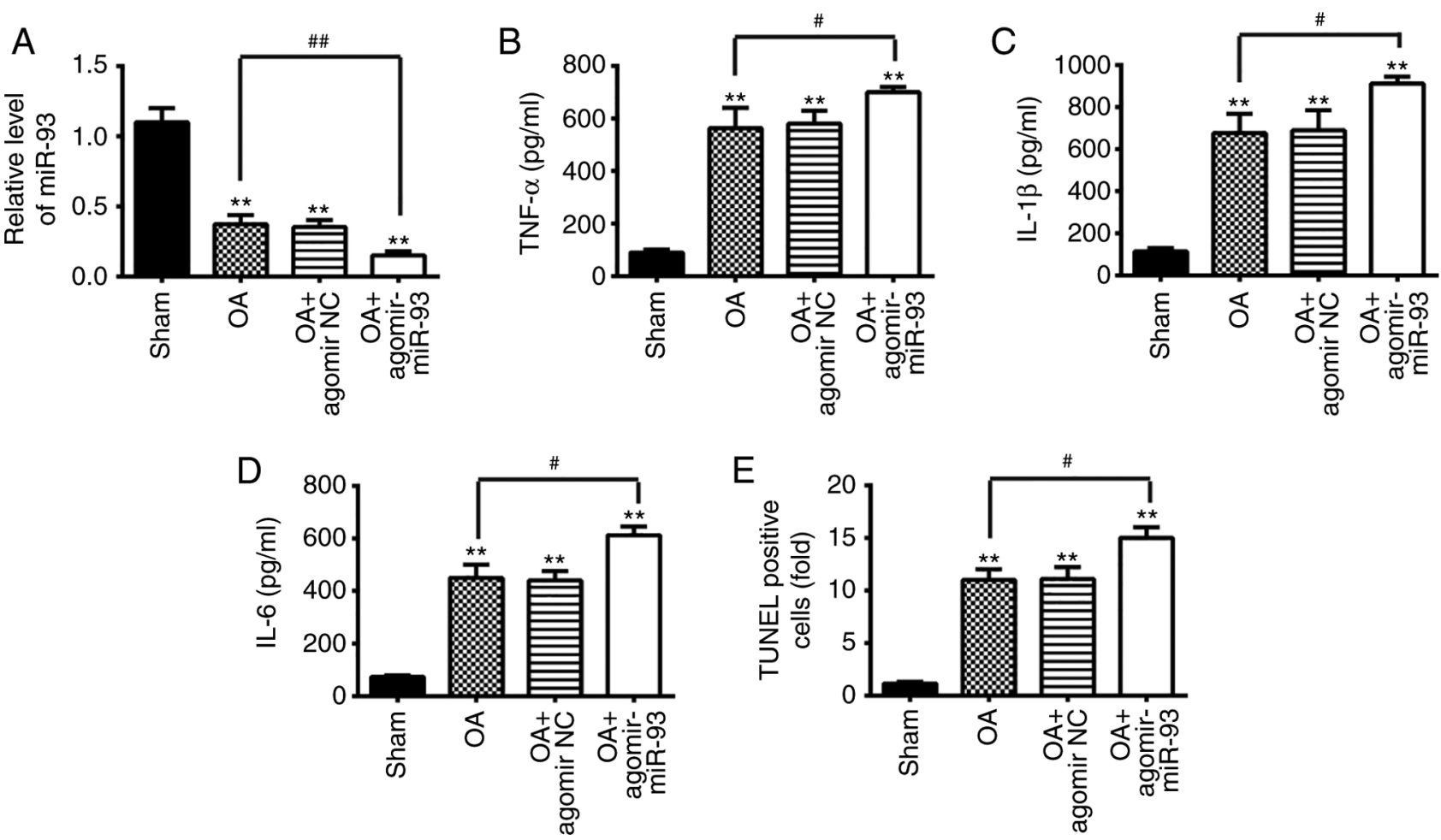

Figure 7. Antagomir-93 exacerbates apoptosis and inflammation in OA mice. The mouse model of OA was injected with antagomir-miR-93 (5 nmol) via intra-articular injection. The mice were subjected to medial meniscectomy tear surgery and treated with antagomir-negative control as the negative control. After 2 weeks, all mice were sacrificed. Subsequently, the articular cartilages of the medial tibial plateau and the synovial fluid were collected for further analysis. (A) Relative expression of miR-93 was determined by reverse transcription-quantitative polymerase chain reaction analysis. Release of (B) TNF- $\alpha$, (C) IL-1 $\beta$, and (D) IL-6 inflammatory cytokines was measured using ELISA kits. (E) Apoptotic cells were determined using TUNEL staining. Data are presented as the mean \pm standard deviation of three independent experiments. ${ }^{* *} \mathrm{P}<0.01$, vs. Sham group; ${ }^{\sharp} \mathrm{P}<0.05$, ${ }^{\# \#} \mathrm{P}<0.01$, vs. OA group. Toll-like receptor 4; miR, microRNA; OA, osteoarthritis; NC, negative control; TNF, tumor necrosis factor; IL, interleukin; TUNEL, terminal deoxynucleotidyl transferase-mediated dUTP-biotin nick-end labeling.

Antagomir-93 exacerbates apoptosis and inflammation in $O A$ mice. Subsequently, the present study evaluated the effects of miR-93 antagomir in OA mice. The mouse model of OA was injected with antagomir-miR-93 (5 nmol) via intra-articular injection. As shown in Fig. 7A, the expression of miR-93 was significantly lower in the articular cartilage tissues from $\mathrm{OA}+$ antagomir-miR-93 group than that in OA group. The results of the ELISA analysis showed that the expression levels of pro-inflammatory cytokines (TNF- $\alpha$, IL-1 $\beta$ and IL-6) were markedly higher in the OA + antagomir-miR-93 group than levels in the OA group (Fig. 7B-D). Furthermore, compared with the OA group, more TUNEL-positive cells were observed in the OA + antagomir-miR-93 group (Fig. 7E). These data indicated that antagomir-93 exacerbates inflammation and apoptosis in OA mice.

\section{Discussion}

The present study demonstrated that miR-93 was significantly decreased in articular cartilage tissues from the OA mice model and in the LPS-induced chondrocytes. The overexpression of miR-93 significantly inhibited LPS-induced cell apoptosis and pro-inflammatory cytokine production in vitro and in vivo. TLR4 was identified as a direct target of miR-93 and the overexpression of TLR4 reversed the biological effects of miR-93. In view of this, we speculate that miR-93 may potentially provide a new strategy for the treatment of OA.
Increasing evidence has indicated that miRNAs are involved in the pathogenesis of OA (4). For example, Wu et al showed that the upregulation of miR-24 prevented the occurrence and progression of $\mathrm{OA}$ through the mitogen-activated protein kinase signaling pathway (26). miR-21 was found to be significantly increased in human OA tissues and the overexpression of miR-21 improved chondrogenesis by targeting growth differentiation factor 5 (27). Si et al found that the expression of miR-140 was significantly reduced in human OA chondrocytes, and intra-articular injection of miR-140 alleviated the progression of OA by modulating cartilage extracellular matrix homeostasis in rats (13). In the present study, using a miRNA microarray, it was found that miR-93was significantly downregulated in articular cartilage tissues from the OA mice model and LPS-induced OA cell model. These data suggest that miR-93 may be involved in the pathogenesis of OA.

Previous studies have shown that miR-93 is important in inflammatory diseases. For example, Ma et al found that the upregulation of miR-93 reduced the inflammatory response by negatively targeting SPP1 in mouse cardiac microvascular endothelial cell injury (28). Tian et al demonstrated that miR-93 was reduced in cerebral ischemia reperfusion (CIR) mouse brains and that ago-miR-93 injection inhibited inflammatory responses and the rate of cell apoptosis following CIR injury (19). Xu et al found that the overexpression of miR-93 suppressed inflammatory cytokine production in LPS-stimulated murine macrophages by targeting interleukin-1 
receptor-associated kinase 4 (29). To the best of our knowledge, no other data are available on the roles of miR-93 in the regulation of inflammatory responses associated with OA. In the present study, the LPS-induced OA cell model was used to examine the regulatory mechanism of miR-93 on inflammation and apoptosis. The results showed that the overexpression of miR-93 suppressed the inflammation and cell apoptosis induced by LPS in chondrocytes, and in vivo. The findings also confirmed that miR-93 exerted its protective effects against OA through suppressing inflammation and apoptosis.

TLR4, one of the pathogen recognition receptors, has received attention in OA for its ability to recognize microbial or host-derived ligands found in OA $(30,31)$. TLR4 has been shown to be expressed in OA cartilage and on activated synoviocytes (32), and its expression in joint tissues is increased with aging and with increasing severity of OA (33). Li et al showed that inhibiting the expression of TLR4 in cartilage lessened the severity of OA in the rat model (34). miRNAs have been found to affect the activation of TLR4 (35-38). For example, Chen et al found that miR-20a negatively regulated TLR4 signaling under atherosclerotic risk (39). A previous study performed by Li et al showed that the overexpression of miR-93 has a protective effect on an Angiotensin II-induced cardiac hypertrophy model by directly targeting TLR4 (40). In the present study, TLR4 was identified as a target of miR-93 in the chondrocytes and negatively regulated by miR-93. Therefore, it was hypothesized that miR-93 protects chondrocytes from LPS-induced inflammation through targeting TLR4 signaling. As expected, the overexpression of TLR4 significantly abrogated the inhibitory effects of miR-93 on inflammation and apoptosis in LPS-induced chondrocytes. Taken together, these results indicate that the miR-93/TLR4 axis may represent a novel and promising target for the treatment of OA.

$\mathrm{NF}-\kappa \mathrm{B}$ is an important transcription factor and is key in the induction of inflammatory injury (41). Upon stimulation by LPS, NF- $\kappa \mathrm{B}$ detaches from I $\mathrm{B}$ and translocates into the nucleus to regulate inflammatory cytokine expression, which induces destruction of the articular joint, leading to the onset and progression of OA (42). TLR4 has been reported as an inducer of the NF- $\kappa$ B inflammatory signaling pathway $(25,43)$. A previous study showed that the TLR4/NF-kB signaling pathway is a vital mechanism for the regulation of inflammatory responses in human OA chondrocytes (44). Given the association between TLR4 and miR-93, it was hypothesized that miR-93 is important in inflammatory responses by mediating the TLR4/NF- $\kappa \mathrm{B}$ signaling pathway. In the present study, it was observed that the overexpression of miR-93 significantly inhibited the LPS-induced activation of NF- $\kappa \mathrm{B}$ in vitro and in vivo. These results suggested that miR-93 inhibited the LPS-induced inflammatory response by inhibiting the TLR4/NF- $\mathrm{B}$ signaling pathway.

In conclusion, the present study demonstrated that miR-93 inhibits LPS-induced inflammatory responses and cell apoptosis via inhibition of the TLR4/NF- $\mathrm{B}$ pathway. The miR-93/TLR4/NF- $\kappa$ B axis may serve as a promising target for the treatment of OA.

\section{Acknowledgements}

Not applicable.

\section{Funding}

The present study was supported by the Fund of Science and Technology Development Project of Kaifeng City (grant no. 2017123) and the Scientific Research Project of Administration of Traditional Chinese Medicine of Henan Province (grant no. 2017ZY3044).

\section{Availability of data and materials}

All data generated and analyzed during the present study are included in this article.

\section{Authors' contributions}

YD, LW and QZ performed the experiments, contributed to data analysis and wrote the manuscript. YD, LW, QZ, ZW and LK analyzed the data. QZ conceptualized the study design, and contributed to data analysis and experimental materials. All authors read and approved the final manuscript.

\section{Ethics approval and consent to participate}

All individuals provided informed consent for the use of human specimens for clinical experiments. The present study was approved by the Ethics Committees of Huaihe Hospital of Henan University.

\section{Patient consent for publication}

Not applicable.

\section{Competing interests}

The authors declare that they have no competing interests.

\section{References}

1. Taruc-Uy RL and Lynch SA: Diagnosis and treatment of osteoarthritis. Prim Care 40: 821-836, vii, 2013.

2. Fransen M, McConnell S, Harmer AR, Van der Esch M, Simic M and Bennell KL: Exercise for osteoarthritis of the knee: A Cochrane systematic review. Br J Sports Med 49: 1554-1557, 2015.

3. Aigner T, Söder S, Gebhard PM, McAlinden A and Haag J: Mechanisms of disease: Role of chondrocytes in the pathogenesis of osteoarthritis-structure, chaos and senescence. Nat Clin Pract Rheumatol 3: 391-399, 2007.

4. Le LT and Clark IM: Review: The role of microRNAs in osteoarthritis and chondrogenesis. Arthritis Rheum 65: 1963-1974, 2013.

5. Bartel DP: MicroRNAs: Genomics, biogenesis, mechanism, and function. Cell 116: 281-297, 2004.

6. Ambros V: The functions of animal microRNAs. Nature 431: 350-355, 2004.

7. Zhang G, Sun Y, Wang Y, Liu R, Bao Y and Li Q: MiR-502-5p inhibits IL-1 $\beta$-induced chondrocyte injury by targeting TRAF2 . Cell Immunol 302: 50-57, 2016.

8. Wu C, Tian B, Qu X, Liu F, Tang T, Qin A, Zhu Z and Dai K: MicroRNAs play a role in chondrogenesis and osteoarthritis (review). Int J Mol Med 34: 13-23, 2014.

9. Junker A, Krumbholz M, Eisele S, Mohan H, Augstein F, Bittner R, Lassmann H, Wekerle H, Hohlfeld R and Meinl E: MicroRNA profiling of multiple sclerosis lesions identifies modulators of the regulatory protein CD47. Brain 132: 3342-3352, 2009.

10. Zhang H, Song B and Pan Z: Downregulation of microRNA-9 increases matrix metalloproteinase-13 expression levels and facilitates osteoarthritis onset. Mol Med Rep 17: 3708-3714, 2018. 
11. Lu J, Ji ML, Zhang XJ, Shi PL, Wu H, Wang $\mathrm{C}$ and Im HJ: MicroRNA-218-5p as a potential target for the treatment of human osteoarthritis. Mol Ther 25: 2676-2688, 2017.

12. Qi J, Qiao Y, Wang P, Li S, Zhao W and Gao C: microRNA-210 negatively regulates LPS-induced production of proinflammatory cytokines by targeting NF- $\mathrm{KB} 1$ in murine macrophages. FEBS Lett 586: 1201-1207, 2012.

13. Si HB, Zeng Y, Liu SY, Zhou ZK, Chen YN, Cheng JQ, Lu YR and Shen B: Intra-articular injection of microRNA-140 (miRNA-140) alleviates osteoarthritis (OA) progression by modulating extracellular matrix (ECM) homeostasis in rats. Osteoarthritis Cartilage 25: 1698-1707, 2017.

14. Glasson SS, Blanchet TJ and Morris EA: The surgical destabilization of the medial meniscus (DMM) model of osteoarthritis in the 129/SvEv mouse. Osteoarthritis Cartilage 15: 1061-1069, 2007.

15. Yang Q, Zhang D, Li Y, Li Y and Li Y: Paclitaxel alleviated liver injury of septic mice by alleviating inflammatory response via microRNA-27a/TAB3/NF- $\kappa$ B signaling pathway. Biomed Pharmacother 97: 1424-1433, 2018.

16. Livak KJ and Schmittgen TD: Analysis of relative gene expression data using real-time quantitative PCR and the 2(-Delta Delta C(T)) method. Methods 25: 402-408, 2001.

17. Liu LJ, Yu JJ and Xu XL: MicroRNA-93 inhibits apoptosis and promotes proliferation, invasion and migration of renal cell carcinoma ACHN cells via the TGF-beta/Smad signaling pathway by targeting RUNX3. Am J Transl Res 9: 3499-3513, 2017.

18. Ke ZP, Xu P, Shi Y and Gao AM: MicroRNA-93 inhibits ischemia-reperfusion induced cardiomyocyte apoptosis by targeting PTEN. Oncotarget 7: 28796-28805, 2016.

19. Tian F, Yuan C, Hu L and Shan S: MicroRNA-93 inhibits inflammatory responses and cell apoptosis after cerebral ischemia reperfusion by targeting interleukin-1 receptor-associated kinase 4. Exp Ther Med 14: 2903-2910, 2017.

20. Canagarajah BJ, Khokhlatchev A, Cobb MH and Goldsmith EJ: Activation mechanism of the MAP kinase ERK2 by dual phosphorylation. Cell 90: 859-869, 1997.

21. Huang D, Zhao Q, Liu H, Guo Y and Xu H: PPAR- $\alpha$ agonist WY-14643 inhibits LPS-induced inflammation in synovial fibroblasts via NF- $\kappa$ B pathway. J Mol Neurosci 59: 544-553, 2016

22. Zhao C, Wang Y, Jin H and Yu T: Knockdown of microRNA-203 alleviates LPS-induced injury by targeting MCL-1 in C28/I2 chondrocytes. Exp Cell Res 359: 171-178, 2017

23. Wang Q, Rozelle AL, Lepus CM, Scanzello CR, Song JJ, Larsen DM, Crish JF, Bebek G, Ritter SY, Lindstrom TM, et al: Identification of a central role for complement in osteoarthritis. Nat Med 17: 1674-1679, 2011.

24. Chen C, Chen W, Li Y, Dong Y, Teng X, Nong Z, Pan X, Lv L, Gao Y and Wu G: Hyperbaric oxygen protects against myocardial reperfusion injury via the inhibition of inflammation and the modulation of autophagy. Oncotarget 8: 111522-111534, 2017.

25. Cao C, Yin C, Shou S, Wang J, Yu L, Li X and Chai Y: Ulinastatin protects against LPS-induced acute lung injury by attenuating TLR4/NF- $\kappa \mathrm{B}$ pathway activation and reducing inflammatory mediators. Shock 50: 595-605, 2018.

26. Wu YH, Liu W, Zhang L, Liu XY, Wang Y, Xue B, Liu B, Duan R, Zhang B and Ji Y: Effects of microRNA-24 targeting $\mathrm{C}$-myc on apoptosis, proliferation and cytokine expressions in chondrocytes of rats with osteoarthritis via MAPK signaling pathway. J Cell Biochem 119: 7944-7958, 2018.

27. Zhang Y, Jia J, Yang S, Liu X, Ye S and Tian H: MicroRNA-21 controls the development of osteoarthritis by targeting GDF-5 in chondrocytes. Exp Mol Med 46: e79, 2014.

28. Ma SX, Bai ZF, Wang W and Wu HY: Effects of Microrna-93 on mouse cardiac microvascular endothelial cells injury and inflammatory response by mediating SPP1 through the NF-KB pathway. J Cell Biochem, Dec 12, 2017 Doi: 10.1002/jcb.26567.
29. Xu Y, Jin H, Yang X, Wang L, Su L, Liu K, Gu Q and Xu X: MicroRNA-93 inhibits inflammatory cytokine production in LPS-stimulated murine macrophages by targeting IRAK4. FEBS Lett 588: 1692-1698, 2014.

30. Abella V, Scotece M, Conde J, López V, Pirozzi C, Pino J, Gómez R, Lago F, González-Gay MÁ and Gualillo O: The novel adipokine progranulin counteracts IL-1 and TLR4-driven inflammatory response in human and murine chondrocytes via TNFR1. Sci Rep 6: 20356, 2016.

31. Wang P, Zhu F, Tong Z and Konstantopoulos K: Response of chondrocytes to shear stress: Antagonistic effects of the binding partners Toll-like receptor 4 and caveolin-1. FASEB J 25: 3401-3415, 2011.

32. Kim HA, Cho ML, Choi HY, Yoon CS, Jhun JY, Oh HJ and Kim HY: The catabolic pathway mediated by Toll-like receptors in human osteoarthritic chondrocytes. Arthritis Rheum 54: 2152-2163, 2006.

33. Goldring MB: Chondrogenesis, chondrocyte differentiation, and articular cartilage metabolism in health and osteoarthritis. Ther Adv Musculoskelet Dis 4: 269-285, 2012.

34. Li J, Xie ZG, Xie Y and Dong QR: Calcitonin treatment is associated with less severe osteoarthritis and reduced toll-like receptor levels in a rat model. J Orthop Sci 19: 1019-1027, 2014.

35. Chen Y, Wu Z, Yuan B, Dong Y, Zhang L and Zeng Z: MicroRNA-146a-5p attenuates irradiation-induced and LPS-induced hepatic stellate cell activation and hepatocyte apoptosis through inhibition of TLR4 pathway. Cell Death Dis 9: 22, 2018.

36. Bao CX, Zhang DX, Wang NN, Zhu XK, Zhao Q and Sun XL: MicroRNA-335-5p suppresses lower extremity deep venous thrombosis by targeted inhibition of PAI-1 via the TLR4 signaling pathway. J Cell Biochem 119: 4692-4710, 2018.

37. Wang Y, Zheng F, Gao G, Yan S, Zhang L, Wang L, Cai X, Wang X, Xu D and Wang J: MiR-548a-3p regulates inflammatory response via TLR4/NF-kappaB signaling pathway in rheumatoid arthritis. J Cell Biochem Jan 6, 2018. Doi: 10.1002/jcb.26659.

38. Jiang W, Liu G and Tang W: MicroRNA-182-5p ameliorates liver ischemia-reperfusion injury by suppressing toll-like receptor 4 . Transplant Proc 48: 2809-2814, 2016.

39. Chen M, Li W, Zhang Y and Yang J: MicroRNA-20a protects human aortic endothelial cells from Ox-LDL-induced inflammation through targeting TLR4 and TXNIP signaling. Biomed Pharmacother 103: 191-197, 2018.

40. Li Y, Wang J, Sun L and Zhu S: LncRNA myocardial infarctionassociated transcript (MIAT) contributed to cardiac hypertrophy by regulating TLR4 via miR-93. Eur J Pharmacol 818: 508-517, 2018.

41. Oeckinghaus A and Ghosh S: The NF-kappaB family of transcription factors and its regulation. Cold Spring Harb Perspect Biol 1: a000034, 2009.

42. Rigoglou $\mathrm{S}$ and Papavassiliou AG: The NF- $\kappa$ B signalling pathway in osteoarthritis. Int J Biochem Cell Biol 45: 2580-2584, 2013.

43. Cao SG, Chen R, Wang H, Lin LM and Xia XP: Cryptotanshinone inhibits prostaglandin E2 production and COX-2 expression via suppression of TLR4/NF-kappaB signaling pathway in LPS-stimulated Caco-2 cells. Microb Pathog 116: 313-317, 2018.

44. Fu Y, Lei J, Zhuang Y, Zhang K and Lu D: Overexpression of HMGB1 A-box reduced IL-1beta-induced MMP expression and the production of inflammatory mediators in human chondrocytes. Exp Cell Res 349: 184-190, 2016.

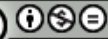

This work is licensed under a Creative Commons Attribution-NonCommercial-NoDerivatives 4.0 International (CC BY-NC-ND 4.0) License. 